\title{
Common fixed-point results for generalized Berinde-type contractions which involve altering distance functions
}

\author{
Fawzia Shaddad $^{1 *}$, Mohd Salmi Md Noorani ${ }^{1}$ and Saud M Alsulami ${ }^{2}$
}

\section{"Correspondence:}

fzsh99@gmail.com

${ }^{1}$ School of Mathematical Sciences,

Faculty of Science and Technology,

University Kebangsaan Malaysia,

UKM, Bangi, Selangor Darul Ehsan

43600, Malaysia

Full list of author information is

available at the end of the article

\begin{abstract}
In this paper, the existence and the uniqueness of a common fixed point for two self-mappings satisfying some generalized Berinde-type contractions which involve an altering distance function with $\lambda \in[0,1]$ is established. Our theorems extend, unify, and generalize several existing results in the literature. An application of an integral equation is presented.
\end{abstract}

MSC: 54H25; 54C60; 54E50

Keywords: metric space; common fixed point; generalized Berinde-type contractions; Urysohn integral equations

\section{Introduction and preliminaries}

Fixed-point theory is one of the most fruitful and effective tools in mathematics which has enormous applications within as well as outside mathematics. In 1922, Banach established the famous fixed-point theorem which is called the Banach contraction principle. This principle is a forceful tool in nonlinear analysis. It has many applications in solving nonlinear equations.

Later, Berinde [1-5] studied many interesting fixed-point theorems for many kinds of contraction mappings. In [3] and [4], he defined the almost contraction map as follows.

Definition 1.1 Let $(X, d)$ be a metric space. A map $f: X \rightarrow X$ is called an almost contraction if there exist a constant $\lambda \in[0,1)$ and some $L \geq 0$ such that

$$
d(f x, f y) \leq \lambda d(x, y)+L d(y, f x)
$$

for all $x, y \in X$.

Let $(X, d)$ be a metric space. A map $f: X \rightarrow X$ is said to satisfy 'condition (B)' if there exist a constant $\lambda \in[0,1)$ and some $L \geq 0$ such that for all $x, y \in X$.

$$
d(f x, f y) \leq \lambda d(x, y)+L \min \{d(x, f x), d(y, f y), d(x, f y), d(y, f x)\} .
$$

Recently, Babu et al. [6] considered the class of mappings that satisfy 'condition (B)'.

More recently, Abbas and Ilic in [7] introduced the following definition.

(02014 Shaddad et al.; licensee Springer. This is an Open Access article distributed under the terms of the Creative Commons Attribution License (http://creativecommons.org/licenses/by/2.0), which permits unrestricted use, distribution, and reproduction in any medium, provided the original work is properly cited. 
Definition 1.2 Let $f$ and $g$ be two self-maps on a metric space $(X, d)$. A map $f$ is called generalized almost $g$-contraction if there exist a constant $\lambda \in[0,1)$ and some $L \geq 0$ such that

$$
d(f x, f y) \leq \lambda M(x, y)+L \min \{d(g x, f x), d(g y, f y), d(g x, f y), d(g y, f x)\}
$$

for all $x, y \in X$, where $M(x, y)=\max \left\{d(g x, g y), d(g x, f x), d(f y, g y), \frac{1}{2}(d(f x, g y)+d(g x, f y))\right\}$.

If $g=I_{X}, I_{X}$ is the identity map on $X$, then they note that $f$ satisfies 'generalized condition (B)'.

Furthermore, Cirić et al. [8] introduced the concept of the almost generalized contractive condition as follows.

Definition 1.3 Let $f$ and $g$ be two self-maps on a metric space $(X, d)$. They are said to satisfy almost generalized contractive condition if there exist a constant $\lambda \in[0,1)$ and some $L \geq 0$ such that

$$
\begin{aligned}
d(f x, g y) \leq & \lambda \max \left\{d(x, y), d(x, f x), d(y, g y), \frac{1}{2}(d(f x, y)+d(x, g y))\right\} \\
& +L \min \{d(x, f x), d(y, g y), d(x, g y), d(y, f x)\}
\end{aligned}
$$

for all $x, y \in X$.

A new category of contractive fixed-point problems was addressed by Khan et al. [9]. In their study they introduced the notion of an altering distance function, which is a control function that alters the distance between two points in a metric space.

Definition 1.4 The function $\psi:[0, \infty) \rightarrow[0, \infty)$ is called an altering distance function if the following properties are satisfied:

(i) $\psi$ is continuous and nondecreasing;

(ii) $\psi(t)=0 \Leftrightarrow t=0$.

In the literature, there has been extensive research on common fixed points by using Berinde-type contractions, see [10, 11], by using an altering distance function, see [12-14] and by using many other kinds of methods, see [15-17].

The aim of this work is to prove that there is a unique common fixed point for two selfmappings satisfying some generalized Berinde-type contractions which involve an altering distance function with $\lambda \in[0,1]$. These results extend and generalize several well-known compatible recent and classical results in the literature. As an application, the existence of a solution for the Urysohn integral equation is presented.

\section{Main results}

Theorem 2.1 Let $(X, d)$ be a complete metric space. Suppose $\psi:[0, \infty) \rightarrow[0, \infty)$ is an altering distance function and $\varphi:[0, \infty) \rightarrow[0, \infty)$ is a lower semi-continuous function with $\varphi(t)=0$ if and only if $t=0$. Moreover, suppose that $f$ and $g$ are self-maps satisfying the inequality

$$
\psi(d(f x, g y)) \leq \psi(\lambda u(x, y))-\varphi(\lambda u(x, y))+L N(x, y)
$$


where

$$
u(x, y) \in\left\{d(x, y), d(x, f x), d(y, g y), \frac{1}{2}(d(f x, y)+d(x, g y))\right\}
$$

and

$$
N(x, y)=\min \{d(x, y), d(x, f x), d(y, g y), d(f x, y), d(x, g y)\},
$$

with $L \geq 0$ and $0 \leq \lambda \leq 1$. Then $f$ and $g$ have a unique common fixed point.

Proof We prove the theorem in several steps.

Step 1 . Let $x_{0} \in X$ be an arbitrary point.

Taking $x_{1}=f x_{0}$ and $x_{2}=g x_{1}$, then let $x_{3}=f x_{2}$ and $x_{4}=g x_{3}$. Continue in this way, we can choose a sequence $\left\{x_{n}\right\}$ in $X$ so that

$$
x_{2 n+1}=f x_{2 n}
$$

and

$$
x_{2 n+2}=g x_{2 n+1}
$$

for all $n=0,1,2, \ldots$. Let

$$
d_{n}=d\left(x_{n}, x_{n+1}\right) .
$$

We will prove that $\left\{d_{n}\right\}$ is a decreasing sequence which converges to 0 .

If $n$ is an even number, put $x=x_{n}$ and $y=x_{n-1}$ in (2.1). We get

$$
\begin{aligned}
\psi\left(d\left(x_{n+1}, x_{n}\right)\right) & =\psi\left(d\left(f x_{n}, g x_{n-1}\right)\right) \\
& \leq \psi\left(\lambda u\left(x_{n}, x_{n-1}\right)\right)-\varphi\left(\lambda u\left(x_{n}, x_{n-1}\right)\right)+L N\left(x_{n}, x_{n-1}\right),
\end{aligned}
$$

where

$$
u\left(x_{n}, x_{n-1}\right) \in\left\{d\left(x_{n}, x_{n-1}\right), d\left(x_{n}, f x_{n}\right), d\left(x_{n-1}, g x_{n-1}\right), \frac{1}{2}\left(d\left(f x_{n}, x_{n-1}\right)+d\left(x_{n}, g x_{n-1}\right)\right)\right\}
$$

and

$$
N\left(x_{n}, x_{n-1}\right)=\min \left\{d\left(x_{n}, x_{n-1}\right), d\left(x_{n}, f x_{n}\right), d\left(x_{n-1}, g x_{n-1}\right), d\left(f x_{n}, x_{n-1}\right), d\left(x_{n}, g x_{n-1}\right)\right\},
$$

i.e.,

$$
N\left(x_{n}, x_{n-1}\right)=0 .
$$

Thus, we have

$$
\psi\left(d\left(x_{n}, x_{n+1}\right)\right) \leq \psi\left(\lambda u\left(x_{n}, x_{n-1}\right)\right)-\varphi\left(\lambda u\left(x_{n}, x_{n-1}\right)\right),
$$


where

$$
u\left(x_{n}, x_{n-1}\right) \in\left\{d\left(x_{n-1}, x_{n}\right), d\left(x_{n}, x_{n+1}\right), \frac{1}{2} d\left(x_{n-1}, x_{n+1}\right)\right\} .
$$

If $x_{n}=x_{n+1}$ for some $n \geq 0$, then the proof will be finished. Therefore, we suppose that $x_{n} \neq x_{n+1}$ for all $n \geq 0$. Now, we shall show that $d\left(x_{n}, x_{n+1}\right) \leq d\left(x_{n-1}, x_{n}\right)$. Arguing by contradiction, we assume $d\left(x_{n}, x_{n+1}\right)>d\left(x_{n-1}, x_{n}\right)$. Therefore, we have three cases.

Case 1: $u\left(x_{n}, x_{n-1}\right)=d\left(x_{n-1}, x_{n}\right)$. Then

$$
\psi\left(d\left(x_{n}, x_{n+1}\right)\right) \leq \psi\left(\lambda d\left(x_{n-1}, x_{n}\right)\right)-\varphi\left(\lambda d\left(x_{n-1}, x_{n}\right)\right)<\psi\left(\lambda d\left(x_{n-1}, x_{n}\right)\right) .
$$

Since $\psi$ is increasing, we have $d\left(x_{n}, x_{n+1}\right)<\lambda d\left(x_{n-1}, x_{n}\right)$, which is a contradiction.

Case 2: $u\left(x_{n}, x_{n-1}\right)=d\left(x_{n}, x_{n+1}\right)$. Then

$$
\psi\left(d\left(x_{n}, x_{n+1}\right)\right) \leq \psi\left(\lambda d\left(x_{n}, x_{n+1}\right)\right)-\varphi\left(\lambda d\left(x_{n}, x_{n+1}\right)\right)<\psi\left(\lambda d\left(x_{n}, x_{n+1}\right)\right) .
$$

Since $\psi$ is increasing, we have $d\left(x_{n}, x_{n+1}\right)<\lambda d\left(x_{n}, x_{n+1}\right)$, which is impossible.

Case 3: $u\left(x_{n}, x_{n-1}\right)=\frac{1}{2} d\left(x_{n-1}, x_{n+1}\right)$. Then

$$
\psi\left(d\left(x_{n}, x_{n+1}\right)\right) \leq \psi\left(\frac{\lambda}{2} d\left(x_{n-1}, x_{n+1}\right)\right)-\varphi\left(\frac{\lambda}{2} d\left(x_{n-1}, x_{n+1}\right)\right) \leq \psi\left(\frac{\lambda}{2} d\left(x_{n-1}, x_{n+1}\right)\right) .
$$

Since $\psi$ is increasing, we have

$$
d\left(x_{n}, x_{n+1}\right) \leq \frac{\lambda}{2} d\left(x_{n-1}, x_{n+1}\right) \leq \frac{\lambda}{2}\left(d\left(x_{n-1}, x_{n}\right)+d\left(x_{n}, x_{n+1}\right)\right),
$$

which leads to

$$
d\left(x_{n}, x_{n+1}\right) \leq \frac{\lambda}{2-\lambda} d\left(x_{n-1}, x_{n}\right),
$$

but $d\left(x_{n}, x_{n+1}\right)>d\left(x_{n-1}, x_{n}\right)$, therefore

$$
d\left(x_{n}, x_{n+1}\right)<\frac{\lambda}{2-\lambda} d\left(x_{n}, x_{n+1}\right),
$$

which is impossible since $\lambda /(2-\lambda) \leq 1$. Hence, from the above we obtain $d\left(x_{n}, x_{n+1}\right) \leq$ $d\left(x_{n-1}, x_{n}\right)$.

Similarly, we can prove that $d\left(x_{n}, x_{n+1}\right) \leq d\left(x_{n-1}, x_{n}\right)$ also in the case when $n$ is an odd number.

Therefore, we find that $\left\{d_{n}\right\}$ is a decreasing sequence and bounded below. Thus, $\left\{d_{n}\right\}$ is convergent. Let

$$
d_{n} \rightarrow d \quad \text { as } n \rightarrow \infty
$$

Next, we want to show that $d=0$. We have two cases.

Case 1. When $u\left(x_{n}, x_{n-1}\right) \in\left\{d\left(x_{n-1}, x_{n}\right), d\left(x_{n}, x_{n+1}\right)\right\}$, as $\psi$ is continuous and $\varphi$ is lower semi-continuous and from (2.4) we get

$$
\psi(d) \leq \psi(\lambda d)-\varphi(\lambda d) .
$$


If $\lambda=0$, then we have $\psi(d) \leq 0 \Rightarrow d=0$. If $\lambda \neq 0$, then we have $\varphi(\lambda d) \leq \psi(\lambda d)-\psi(d) \leq 0$. Thus $\varphi(\lambda d)=0$, which implies $d=0$.

Case 2. When $u\left(x_{n}, x_{n-1}\right)=\frac{1}{2} d\left(x_{n-1}, x_{n+1}\right)$, we suppose that $d \neq 0$; then

$$
\begin{aligned}
\psi\left(d_{n}\right) & \leq \psi\left(\frac{\lambda}{2} d\left(x_{n-1}, x_{n+1}\right)\right)-\varphi\left(\frac{\lambda}{2} d\left(x_{n-1}, x_{n+1}\right)\right) \\
& \leq \psi\left(\frac{\lambda}{2} d\left(x_{n-1}, x_{n+1}\right)\right) \\
& \leq \psi\left(\frac{\lambda}{2}\left(d\left(x_{n-1}, x_{n}\right)+d\left(x_{n}, x_{n+1}\right)\right)\right) .
\end{aligned}
$$

Now, we have two subcases.

Subcase 1. $\lambda<1$. Then as $n \rightarrow \infty$ we obtain

$$
\psi(d) \leq \psi(\lambda d)
$$

which leads to a contradiction if $d \neq 0$.

Subcase $2 . \lambda=1$. Then

$$
\psi\left(d_{n}\right) \leq \psi\left(\frac{1}{2} d\left(x_{n-1}, x_{n+1}\right)\right) \leq \psi\left(\frac{1}{2}\left(d\left(x_{n-1}, x_{n}\right)+d\left(x_{n}, x_{n+1}\right)\right)\right) .
$$

As $n \rightarrow \infty$, we have

$$
\psi(d) \leq \psi\left(\frac{1}{2} \lim _{n \rightarrow \infty} d\left(x_{n-1}, x_{n+1}\right)\right) \leq \psi(d) .
$$

Since $\psi$ is an increasing function, we get

$$
\lim _{n \rightarrow \infty} d\left(x_{n-1}, x_{n+1}\right)=2 d
$$

By taking $n \rightarrow \infty$ in $\psi\left(d_{n}\right) \leq \psi\left(\frac{\lambda}{2} d\left(x_{n-1}, x_{n+1}\right)\right)-\varphi\left(\frac{\lambda}{2} d\left(x_{n-1}, x_{n+1}\right)\right)$ and using (2.5), we have

$$
\psi(d) \leq \psi\left(\frac{1}{2}(2 d)\right)-\varphi\left(\frac{1}{2}(2 d)\right)
$$

i.e.

$$
\varphi(d) \leq 0 .
$$

Hence, $\varphi(d)=0$ and then $d=0$.

From the above we obtain $d=0$, i.e.,

$$
d_{n}=d\left(x_{n}, x_{n+1}\right) \rightarrow 0 \quad \text { as } n \rightarrow \infty .
$$

Step 2. We prove that $\left\{x_{n}\right\}$ is a Cauchy sequence. Suppose that $\left\{x_{n}\right\}$ is not a Cauchy sequence, then there exists $\varepsilon>0$ for which we can find subsequences $\left\{x_{n(k)}\right\}$ and $\left\{x_{m(k)}\right\}$ of $\left\{x_{n}\right\}$ with $n(k)>m(k) \geq k$ such that

$$
d\left(x_{n(k)}, x_{m(k)}\right) \geq \varepsilon / k
$$


Furthermore, corresponding to $m(k)$, we can choose $n(k)$ in such a way that it is the smallest integer with $n(k)>m(k)$ and satisfying (2.7). Then

$$
d\left(x_{n(k)-1}, x_{m(k)}\right)<\varepsilon / k .
$$

Then we have

$$
\begin{aligned}
\varepsilon / k & \leq d\left(x_{n(k)}, x_{m(k)}\right) \leq d\left(x_{n(k)}, x_{n(k)-1}\right)+d\left(x_{n(k)-1}, x_{m(k)}\right) \\
& \leq d\left(x_{n(k)}, x_{n(k)-1}\right)+\varepsilon / k,
\end{aligned}
$$

by taking $k \rightarrow \infty$, we obtain

$$
\lim _{k \rightarrow \infty} d\left(x_{n(k)}, x_{m(k)}\right)=0,
$$

which is a contradiction. So, $\left\{x_{n}\right\}$ is a Cauchy sequence in a complete metric space $X$ and hence it is convergent in $X$. Let

$$
\lim _{n \rightarrow \infty} x_{n}=x^{*}
$$

Step 3. Let us now prove that $x^{*}$ is a common fixed point of $f$ and $g$. Put $x=x^{*}$ and $y=x_{2 n+1}$ in (2.1) for all $n$, and we obtain

$$
\psi\left(d\left(f x^{*}, g x_{2 n+1}\right)\right) \leq \psi\left(\lambda u\left(x^{*}, x_{2 n+1}\right)\right)-\varphi\left(\lambda u\left(x^{*}, x_{2 n+1}\right)\right)+L N\left(x^{*}, x_{2 n+1}\right),
$$

where

$$
u\left(x^{*}, x_{2 n+1}\right) \in\left\{d\left(x^{*}, x_{2 n+1}\right), d\left(x^{*}, f x^{*}\right), d\left(x_{2 n+1}, g x_{2 n+1}\right), \frac{1}{2}\left(d\left(f x^{*}, x_{2 n+1}\right)+d\left(x^{*}, g x_{2 n+1}\right)\right)\right\}
$$

and

$$
N\left(x^{*}, x_{2 n+1}\right)=\min \left\{d\left(x^{*}, x_{2 n+1}\right), d\left(x^{*}, f x^{*}\right), d\left(x_{2 n+1}, g x_{2 n+1}\right), d\left(f x^{*}, x_{2 n+1}\right), d\left(x^{*}, g x_{2 n+1}\right)\right\} .
$$

Let $n \rightarrow \infty$, we get

$$
\psi\left(d\left(f x^{*}, x^{*}\right)\right) \leq \psi\left(\lambda \lim _{n \rightarrow \infty} u\left(x^{*}, x_{2 n+1}\right)\right)-\varphi\left(\lambda \lim _{n \rightarrow \infty} u\left(x^{*}, x_{2 n+1}\right)\right),
$$

where

$$
\lim _{n \rightarrow \infty} u\left(x^{*}, x_{2 n+1}\right) \in\left\{0, d\left(x^{*}, f x^{*}\right), \frac{1}{2} d\left(x^{*}, f x^{*}\right)\right\} .
$$

If $d\left(x^{*}, f x^{*}\right) \neq 0$, then

$$
\psi\left(d\left(x^{*}, f x^{*}\right)\right)<\psi\left(\lambda d\left(x^{*}, f x^{*}\right)\right) \text { or } \psi\left(d\left(x^{*}, f x^{*}\right)\right)<\psi\left(\frac{\lambda}{2} d\left(x^{*}, f x^{*}\right)\right),
$$

which is a contradiction. Hence, we obtain

$$
d\left(x^{*}, f x^{*}\right)=0 \quad \text { or } \quad x^{*}=f x^{*} .
$$


Similarly, when we take $x=x_{2 n}$ and $y=x^{*}$ in (2.1) for all $n$ we get

$$
x^{*}=g x^{*} .
$$

Equations (2.8) and (2.9) show that $x^{*}$ is a common fixed point of $f$ and $g$.

Step 4 . Let us now show the uniqueness. Let $y^{*}$ be another common fixed point of $f$ and $g$. Then from (2.1) we have

$$
\psi\left(d\left(f x^{*}, g y^{*}\right)\right)=\psi\left(d\left(x^{*}, y^{*}\right)\right) \leq \psi\left(\lambda u\left(x^{*}, y^{*}\right)\right)-\varphi\left(\lambda u\left(x^{*}, y^{*}\right)\right)+L N\left(x^{*}, y^{*}\right),
$$

where

$$
u\left(x^{*}, y^{*}\right) \in\left\{0, d\left(x^{*}, y^{*}\right)\right\} \text { and } N\left(x^{*}, y^{*}\right)=0 .
$$

Then we obtain $x^{*}=y^{*}$.

Corollary 2.2 Let $(X, d)$ be a complete metric space. Suppose $\psi:[0, \infty) \rightarrow[0, \infty)$ is an altering distance function and $\varphi:[0, \infty) \rightarrow[0, \infty)$ is a lower semi-continuous function with $\varphi(t)=0$ if and only if $t=0$. If $f$ and $g$ are self-maps satisfying the inequality

$$
\psi(d(f x, g y)) \leq \psi(\lambda M(x, y))-\varphi(\lambda M(x, y))+L N(x, y)
$$

where

$$
M(x, y)=\max \left\{d(x, y), d(x, f x), d(y, g y), \frac{1}{2}(d(f x, y)+d(x, g y))\right\}
$$

and

$$
N(x, y)=\min \{d(x, y), d(x, f x), d(y, g y), d(f x, y), d(x, g y)\},
$$

with $L \geq 0$ and $0 \leq \lambda \leq 1$, then $f$ has a unique fixed point.

Proof Since $M(x, y) \in\left\{d(x, y), d(x, f x), d(y, g y), \frac{1}{2}(d(f x, y)+d(x, g y))\right\}$, the result follows from Theorem 2.1.

Remark 2.3 In Corollary 2.2:

(i) If $g=f$ and $\lambda=1$, we obtain a metric version of Theorem 12 of Aydi et al. [10].

(ii) If $L=0$ and $\lambda=1$, we get Theorem 2.1 of Doric [18].

(iii) If $\psi(t)=t, L=0$ and $\lambda=1$, we get Theorem 2.1 of Zhang and Song [19].

By taking $f=g$ and $L=0$ in Corollary 2.2, we obtain the following result.

Corollary 2.4 Let $(X, d)$ be a complete metric space. Suppose $\psi:[0, \infty) \rightarrow[0, \infty)$ is an altering distance function and $\varphi:[0, \infty) \rightarrow[0, \infty)$ is a lower semi-continuous function with $\varphi(t)=0$ if and only if $t=0$. If $f$ is a self-map satisfying the inequality

$$
\psi(d(f x, f y)) \leq \psi(\lambda u(x, y))-\varphi(\lambda u(x, y))
$$


where $u(x, y) \in\left\{d(x, y), d(x, f x), d(y, f y), \frac{1}{2}(d(f x, y)+d(x, f y))\right\}, 0 \leq \lambda \leq 1$, then $f$ has a unique fixed point.

Remark 2.5 Corollary 2.4 extends the main fixed-point result of Dutta and Choudhury [20, Theorem 2.1] and Theorem 2.2 of Doric [18].

If we take $\psi(t)=t$ and $\varphi(t)=(1-k) t$ with $k<1$ in Theorem 2.1, we have the following corollary.

Corollary 2.6 Let $(X, d)$ be a complete metric space. Iff and $g$ are self-maps satisfying the inequality

$$
d(f x, g y) \leq \alpha u(x, y)+L N(x, y)
$$

where

$$
u(x, y) \in\left\{d(x, y), d(x, f x), d(y, g y), \frac{1}{2}(d(f x, y)+d(x, g y))\right\}
$$

and

$$
N(x, y)=\min \{d(x, y), d(x, f x), d(y, g y), d(f x, y), d(x, g y)\},
$$

with $L \geq 0$ and $0 \leq \alpha<1$, then $f$ and $g$ have a unique common fixed point.

If we take $f=g$ in Corollary 2.6 we obtain the following result.

Corollary 2.7 Let $(X, d)$ be a complete metric space. If $f$ is a self-map satisfying the inequality

$$
d(f x, f y) \leq \alpha u(x, y)+L N(x, y)
$$

where

$$
u(x, y) \in\left\{d(x, y), d(x, f x), d(y, f y), \frac{1}{2}(d(f x, y)+d(x, f y))\right\}
$$

and

$$
N(x, y)=\min \{d(x, y), d(x, f x), d(y, f y), d(f x, y), d(x, f y)\},
$$

with $L \geq 0$ and $0 \leq \alpha<1$, then $f$ has a unique fixed point.

By the aid of Lemma 2.1 of [21], we have the following result as a consequence of Corollary 2.7.

Corollary 2.8 Let $(X, d)$ be a complete metric space. Iff and $g$ are self-maps satisfying the inequality

$$
d(f x, f y) \leq \alpha u(g x, g y)+L N(g x, g y),
$$


where

$$
u(g x, g y) \in\left\{d(g x, g y), d(g x, f x), d(g y, f y), \frac{1}{2}(d(f x, g y)+d(g x, f y))\right\}
$$

and

$$
N(g x, g y)=\min \{d(g x, g y), d(g x, f x), d(g y, f y), d(f x, g y), d(g x, f y)\},
$$

with $L \geq 0$ and $0 \leq \alpha<1$, then $f$ and $g$ have a unique common fixed point.

Remark 2.9 Corollary 2.8 extends the results of Abbas et al. [22, Theorem 2.1] and Jleli et al. [23, Corollary 3.2].

\section{Applications: existence of a common solution to Urysohn integral equations}

Throughout this section we take $X=C([a, b], \mathbb{R})$ (the set of continuous functions defined in $I=[a, b])$. We define the metric $d: X \times X \rightarrow \mathbb{R}$ by $d(x, y)=\|x-y\|_{\infty}$ for every $x, y \in X$. Let $\varphi: \mathbb{R}^{+} \rightarrow \mathbb{R}^{+}$be a function such that

- $\varphi$ is lower semi-continuous;

- $\varphi$ is increasing;

- $\varphi(t)=0 \Leftrightarrow t=0$.

Theorem 3.1 Consider the Urysohn integral equations

$$
\begin{aligned}
& x(t)=\int_{a}^{b} K_{1}(t, s, x(s)) d s+h(t), \\
& x(t)=\int_{a}^{b} K_{2}(t, s, x(s)) d s+q(t),
\end{aligned}
$$

where $t \in I \subset \mathbb{R}$ and $x, h, q \in X$. Assume that, for $K_{1}, K_{2}: I \times I \times \mathbb{R} \rightarrow \mathbb{R}$, we have

$$
\left|\int_{a}^{b} K_{1}(t, s, x(s)) d s-\int_{a}^{b} K_{2}(t, s, x(s)) d s+h(t)-q(t)\right| \leq|x(t)-y(t)|-\varphi\left(\sup _{t \in I}|x(t)-y(t)|\right) .
$$

Then there exists a solution to (3.1).

Proof Define $f, g: X \rightarrow X$ by $f(x)=\int_{a}^{b} K_{1}(t, s, x(s)) d s+h(t)$ and $g(x)=\int_{a}^{b} K_{2}(t, s, x(s)) d s+$ $q(t)$. It is obvious that

$$
\|f-g\|_{\infty} \leq\|x-y\|_{\infty}-\varphi\left(\|x-y\|_{\infty}\right)
$$

Thus

$$
d(f x, g y) \leq d(x, y)-\varphi(d(x, y))
$$

for all $x, y \in X$. Now, all the assumptions of Theorem 2.1 are satisfied with $\psi(t)=t$, for all $t \in \mathbb{R}^{+}, u(x, y)=d(x, y)$, and $L=0$. Therefore, $f$ and $g$ have a common fixed point, that is, a solution to the integral equation (3.1). 


\section{Competing interests}

The authors declare that they have no competing interests.

\section{Authors' contributions}

All three authors contributed equally and significantly in writing this paper. All three authors read and approved the final manuscript.

\section{Author details}

'School of Mathematical Sciences, Faculty of Science and Technology, University Kebangsaan Malaysia, UKM, Bangi, Selangor Darul Ehsan 43600, Malaysia. ${ }^{2}$ Department of Mathematics, King Abdulaziz University, P.O. Box 138381, Jeddah, 21323, Saudi Arabia.

\section{Acknowledgements}

The authors would like to acknowledge the financial support received from Universiti Kebangsaan Malaysia under the research grant UKM-DIP-2012-31.

Received: 22 July 2013 Accepted: 10 January 2014 Published: 31 Jan 2014

\section{References}

1. Berinde, $\mathrm{V}$ : Approximating fixed points of weak $\varphi$-contractions using the Picard iteration. Fixed Point Theory 4 , 131-142 (2003)

2. Berinde, V: On the approximation of fixed points of weak contractive mappings. Carpath. J. Math. 19, 7-22 (2003)

3. Berinde, V: Approximating fixed points of weak contractions using the Picard iteration. Nonlinear Anal. Forum 9, 43-53 (2004)

4. Berinde, V: General constructive fixed point theorem for Ćirić-type almost contractions in metric spaces. Carpath. J. Math. 24, 10-19 (2008)

5. Berinde, V: Some remarks on a fixed point theorem for Ćirić-type almost contractions. Carpath. J. Math. 25, 157-162 (2009)

6. Babu, GVR, Sandhya, ML, Kameswari, MVR: A note on a fixed point theorem of Berinde on weak contraction. Carpath. J. Math. 24, 8-12 (2008)

7. Abbas, M, llic, D: Common fixed points of generalized almost nonexpansive mappings. Filomat 24, 11-18 (2010)

8. Ćirić, L, Abbas, M, Saadati, R, Hussain, N: Common fixed points of almost generalized contractive mappings in ordered metric spaces. Appl. Math. Comput. 217, 5784-5789 (2011)

9. Khan, MS, Swaleh, M, Sessa, S: Fixed point theorems by altering distances between the points. Bull. Aust. Math. Soc. 30, 1-9 (1984)

10. Aydi, H, Amor, SH, Karapınar, E: Berinde-type generalized contractions on partial metric spaces. Abstr. Appl. Anal. 2013, Article ID 312479 (2013)

11. Shatanawi, W, Postolache, M: Coincidence and fixed point results for generalized weak contractions in the sense of Berinde on partial metric spaces. Fixed Point Theory Appl. 2013, 54 (2013)

12. Bari, C, Vetro, P: Common fixed points in generalized metric spaces. Appl. Math. Comput. 218, 7322-7325 (2012)

13. Esmaily, J, Vaezpour, SM, Rhoades, BE: Coincidence and common fixed point theorems for a sequence of mappings in ordered metric spaces. Appl. Math. Comput. 219, 5684-5692 (2013)

14. Liu, X, Jesic, S: Common fixed points of a generalized ordered $g$-quasicontraction in partially ordered metric spaces. Fixed Point Theory Appl. 2013, 53 (2013)

15. Aghajani, A, Radenović, S, Roshan, JR: Common fixed point results for four mappings satisfying almost generalized $(S, T)$-contractive condition in partially ordered metric spaces. Appl. Math. Comput. 218, 5665-5670 (2012)

16. Shobkolaei, N, Sedghi, S, Roshan, JR, Altun, I: Common fixed point of mappings satisfying almost generalized $(S, T)$-contractive condition in partially ordered partial metric spaces. Appl. Math. Comput. 219, 443-452 (2012)

17. Roshan, JR, Parvaneh, V, Sedghi, S, Shobkolaei, N, Shatanawi, W: Common fixed points of almost generalized $(\psi, \varphi)_{s}$-contractive mappings in ordered $b$-metric spaces. Fixed Point Theory Appl. 2013, 159 (2013)

18. Doric, D: Common fixed point for generalized $(\psi, \varphi)$-weak contractions. Appl. Math. Lett. 22, 1896-1900 (2009)

19. Zhang, Q, Song, Y: Fixed point theory for generalized $\varphi$-weak contractions. Appl. Math. Lett. 22, 75-78 (2009)

20. Dutta, PN, Choudhury, BS: A generalisation of contraction principle in metric spaces. Fixed Point Theory Appl. 2008 Article ID 406368 (2008)

21. Haghi, RH, Rezapour, S, Shahzad, N: Some fixed point generalizations are not real generalizations. Nonlinear Anal. 74, 1799-1803 (2011)

22. Abbas, M, Babu, GVR, Alemayehu, GN: On common fixed points of weakly compatible mappings satisfying generalized condition (B). Filomat 25, 9-19 (2011)

23. Jleli, M, Karapınar, E, Samet, B: Fixed point results for almost generalized cyclic $(\psi, \varphi)$-weak contractive type mappings with applications. Abstr. Appl. Anal. 2012, Article ID 917831 (2012)

$10.1186 / 1687-1812-2014-24$

Cite this article as: Shaddad et al.: Common fixed-point results for generalized Berinde-type contractions which

involve altering distance functions. Fixed Point Theory and Applications 2014, 2014:24 